\title{
Commentary
}

\section{The Surrogate Mother as a High-Risk Obstetric Patient}

\author{
Nancy E. Reame, RN, PhD \\ Professor \\ School of Nursing and Reproductive Sciences \\ University of Michigan \\ Ann Arbor, Michigan
}

1

number of medical and public policies are recommended in the revised statement on surrogate motherhood by the Committee on Ethics of the American College of Obstetricians and Gynecologists (ACOG) ${ }^{1}$ which expands and replaces the original committee opinion of 1983. Some of the implications with respect to the physician-patient relationship have been laid out in the updated statement, whereas others may only become evident as the practitioner increasingly encounters this population of obstetric patients and the affected families. This commentary examines how the implementation of the revised ethical guidelines may affect and refine future practice.

\section{THE MEDICOLEGAL MILIEU OF A SURROGATE PREGNANCY}

As a public policy recommendation, the committee advocates that surrogate parenting programs be regulated in like fashion as private, nonprofit adoption agencies with similar credentials, operating practices, and safeguards. In addition, the committee recommends that the surrogate mother and the "commissioning couple" have separate medical and legal representation during the arrangement. Such changes would seem to serve the best interests of all parties. Because the primary goal of the agency would be to promote the welfare of the future child, applicant couples would now be required to undergo careful medical and psychological screening evaluations similar to what has been in effect for surrogate mother candidates in most profit-based programs. In addition, the recognition of the need for independent legal representation of the surrogate mother is an important step forward in reducing the potential for exploitation or coercion on the part of the agency.

Thus the obstetrician may soon encounter the surrogate mother who has obtained legal counsel to serve on her behalf as a patient advocate during the pregnancy. Such a scenario may compound an already tenuous physicianpatient relationship given the complex dilemmas in maternal-fetal health care facing obstetricians today.

Alternatively, it is unlikely that many surrogate mothers have the financial resources necessary to obtain legal counsel, independent of agency services. Recent survey data obtained from surrogate parenting programs ${ }^{2}$ and

(C) 1991 by The Jacobs Institute of Women's Health $1049-3867 / 91 / \$ 3.50$ 
studies of surrogate mother samples ${ }^{3,4}$ suggest that surrogate mothers have few financial resources, because a significant number are welfare recipients and most cite financial motivations as a primary reason for participation. In addition, most commissioning couples are unwilling to provide more than a small sum for legal expenses of the surrogate mother, given their vested interests in obtaining custody of the future child. In view of these constraints, it would seem that an inequity in the surrogate parenting relationship could still exist that would disadvantage the surrogate mother and undermine the extent of her understanding and rights in the relationship. In this case, the obstetrician may be the sole patient advocate with respect to health care decisions where there is potential for maternal-fetal conflict.

The ACOG guidelines emphasize the responsibility of the physician in ensuring that the surrogate mother candidate has thoroughly considered the ethical and medical risks, benefits, and contingencies in the event of unforeseen circumstances, such as the prenatal diagnosis of a genetic defect, the death of one of the commissioning parents, or the decision to retain custody of the infant. Under these guidelines, accountability for ensuring informed consent becomes a key component of preconception care. To the extent that fully informed consent is ever possible in a naive individual, this recommendation may have significant medicolegal implications. In view of the current litigious climate, it is no wonder that the ACOG opinion acknowledges that a physician is justified in declining to participate in surrogate motherhood arrangements.

\section{THE SURROGATE GESTATIONAL MOTHER}

The revised committee opinion addresses for the first time the care of the "gestational" surrogate mother who undergoes embryo transfer and serves as carrier of the developing fetus for the purpose of relinquishing the infant at the time of birth to its genetic parents. Under these guidelines, no distinction is made between genetic and gestational surrogate mothers. Both are defined as the sole source of consent for medical decisions about prenatal care and delivery and, in both cases, would retain custody of the infant for a prescribed interval before adoption. The recommendation to treat the gestational surrogate mother as the natural mother ensures the woman's autonomy over her body, so that decisions about her health care are not subsumed by the genetic parents. The feminist writer Gena Corea, in her book The Mother Machine, ${ }^{5}$ has voiced concern over the potential in surrogate mother arrangements for the exploitation of class-distinct, "breeder women" by the wealthy.

On the other hand, the protection of autonomy for the gestational surrogate mother may compromise the rights and responsibilities of the genetic parents. For example, the gestational surrogate would have the right to abort an unrelated fetus if she no longer wished to carry the pregnancy. Alternatively, she could be responsible for custody of an infant with birth defects rejected by the biologic parents. It is interesting that the sperm donor for the gestational surrogate pregnancy would still be regarded as the legal father, whereas the infertile wife would have to adopt her own biologic offspring and be without the right to make decisions concerning postnatal interventions prior to relinquishment by the gestational surrogate mother.

It is noteworthy that the ACOG opinion to equate gestational surrogate motherhood with parenthood is counter to the recent decision by the courts. ${ }^{6}$ In the fall of 1990, Richard N. Parslow, a California Superior Court judge, refused to acknowledge any parental rights of an embryo transfer surrogate, comparing Anna Johnson's participation as a gestational surrogate to that of a foster parent rather than as a natural mother. The decision was in part an 
effort to prevent the creation of a "three-parent, two-natural mom" situation. Under the ACOG guidelines, which recommend a specified period of time after birth during which the surrogate mother is free to depart from the preconception agreement, Ms. Johnson would have the right to retain custody of the infant.

\section{PSYCHOSOCIAL HEALTH RISKS OF A SURROGATE PREGNANCY}

Part of the rationale for recommending the empowerment of the gestational surrogate mother with the rights of the biologic mother is the committee's opinion that the link created through gestation and birth is "more weighty" than the genetic link between the fetus and the commissioning parents. Such a rationale must be examined for supporting evidence. There is an underlying assumption that an emotional tie to the unrelated fetus will form during the pregnancy that is stronger than any developing maternal identity of the nonpregnant, biologic mother who would be denied parental rights to her natural offspring. This perception may be based in part on current understanding of the psychodynamics of pregnancy that prepare a woman for motherhood as well as the significant conflict and ambivalence associated with the placement of a newborn for adoption. In addition, the highly publicized lawsuits between commissioning couples and surrogate mothers who break their contractual agreement have also provided evidence of strong maternal feelings on the part of the surrogate. Indeed, preliminary studies of the psychologic adjustment to a surrogate pregnancy document strong prenatal attachment ${ }^{7}$ as well as significant grief responses at the time of relinquishment. ${ }^{8}$ These types of emotional reactions to a surrogate pregnancy have not come as a surprise to the obstetric health care community. The initial ACOG policy statement of 1983 suggested that significant psychologic stress may exist for surrogate mothers.

What remains unclear, however, is the extent to which a strong maternal-fetal attachment is inherent to the nature of the surrogate pregnancy experience and whether such a relationship serves the best interests of the woman or the future child. Proponents of the surrogate mother movement point to the hundreds of surrogate births that have been arranged without notoriety or dispute. Critics argue that the surrogate mother participants in these "successful" cases may be the most dysfunctional in terms of self-esteem and assertiveness, choosing to suffer in silence.

The National Association of Surrogate Mothers (NASM) proposes that improved guidelines for the selection of surrogate mothers would significantly reduce the likelihood of adverse or dysfunctional maternal health outcomes. ${ }^{9}$ Early data about the psychosocial and cultural makeup of third-party participants in nontraditional childbearing arrangements support the view that improved screening may be necessary. Descriptive studies of traditional surrogate mothers as well as oocyte donors reveal that a majority of individuals have limited psychosocial resources and view their participation as a way to deal with prior traumatic reproductive or family losses. ${ }^{4,10}$

One recommendation called for by NASM, the group of former surrogates, is mandatory counseling for the woman from the time of the contract to a minimum of 6 weeks after the birth of the child. However, such a recommendation subsumes knowledge about the nature of a healthy emotional adjustment to a surrogate pregnancy. Until the optimum adaptational experience has been characterized, it will be difficult to define health care strategies for this purpose. Despite the fact that surrogate mother programs have been in existence for over a decade, anecdotal reports contributed by self-serving private entrepreneurs or media reports of the most publicized cases continue 
to predominate as the primary source of information about the emotional experiences and health outcomes of surrogate parenting arrangements. Relying on this kind of information undermines the quality of public policy decisions regarding the nature and degree of medicolegal regulation or prohibition. Clearly it is time to foster research efforts aimed at the scientific scrutiny of the psychosocial health risks of the surrogate parenting family.

Until there is convincing evidence to the contrary, it seems prudent to view the surrogate mother as a high-risk patient from a psychosocial and perhaps legal perspective, who is in need of careful health screening and ongoing psychological assessment throughout the course of the childbearing experience. This specialized care may extend beyond the scope of traditional obstetric practice and require the participation of a multidisciplinary health specialist team. In view of the potential risks, one can predict that the introduction of surrogate parenting arrangements into the mainstream of childbearing options for infertile couples will only serve to heighten the highly charged conflicts in maternal-fetal health care that exist for the contemporary obstetrician.

\section{REFERENCES}

1. American College of Obstetricians and Gynecologists, Committee on Ethics. Ethical issues in surrogate motherhood (ACOC committee opinion number 88). Washington, DC: ACOG, November 1990.

2. United States Congress, Office of Technology Assessment. Infertility: Medical and social choices (OTA-BA-358). Washington, DC: US Government Printing Office, May 1988.

3. Parker PJ. Motivation of surrogate mothers: Initial findings. Am J Psychiatry 1983;140:117-8.

4. Reame NE, Parker PJ. Surrogate pregnancy: Clinical features of 44 cases. Am J Obstet Gynecol 1990;162:1220-5.

5. Corea G. The mother machine. New York: Harper and Row, 1985.

6. Johnson v Calvert, Cal Super Ct, Orange Co, No. 63-31-90 (October 22, 1990) (appeal pending).

7. Reame NE. Maternal adaptation and psychologic responses to a surrogate pregnancy. J Psychosom Obstet Gynecol 1989;10(suppl):86.

8. Parker PJ. The psychology of the pregnant surrogate mother: A newly updated report of a longitudinal pilot study. Psychiatric News, 18 May, 1984;10-1.

9. Andrews L. Between strangers. New York: Harper and Row, 1989.

10. Schover LR, Reis J, Collins RL, Blankstein J, Kanoti G, Quigley MM. The psychological evaluation of oocyte donors. J Psychosom Obstet Gynecol 1990;11:299-309. 